\title{
Gastrostomy tube use in children with cancer
}

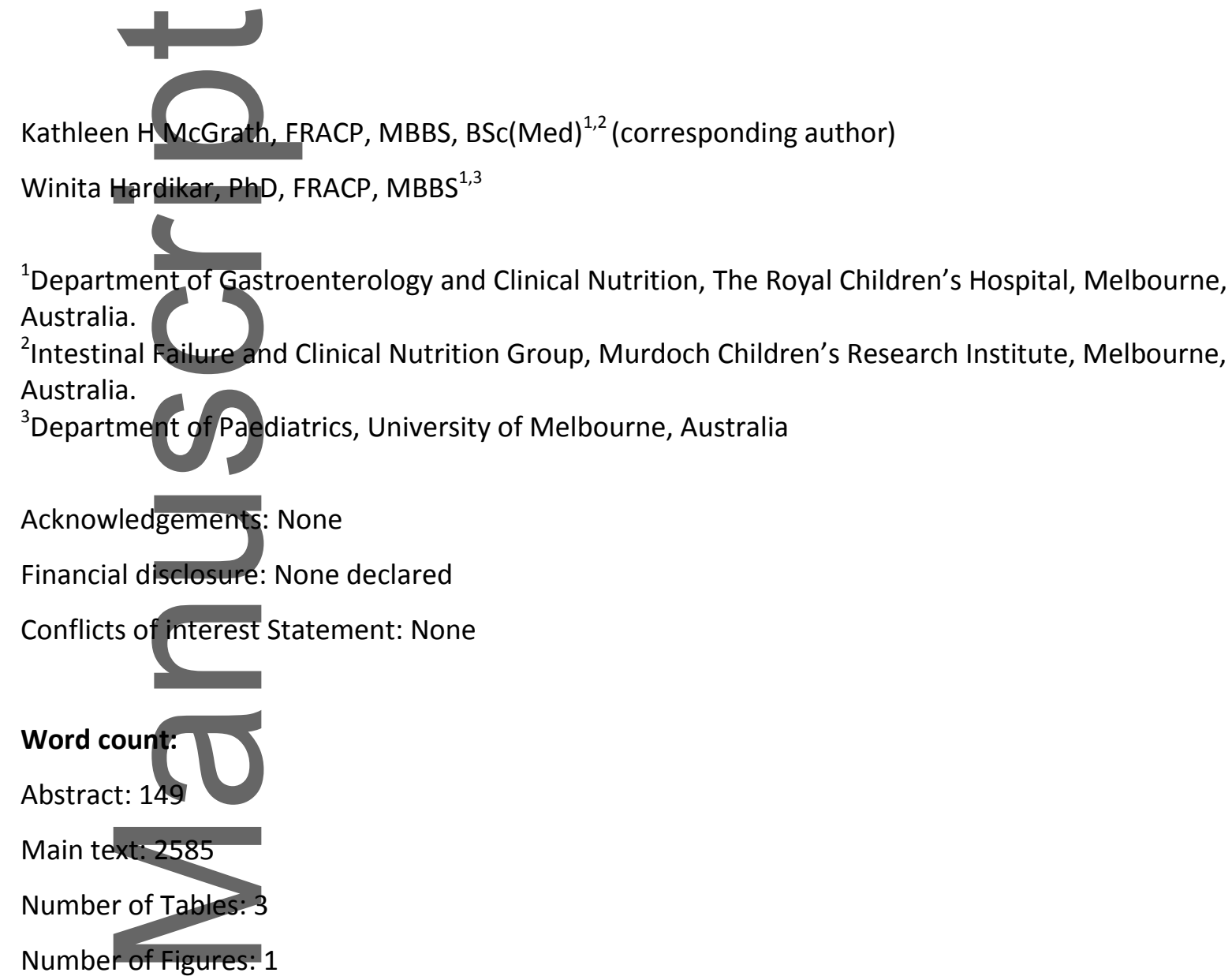

Short running title: Gastrostomy tube use in children with cancer

Keywords: nutrition, nutritional support, pediatric oncology

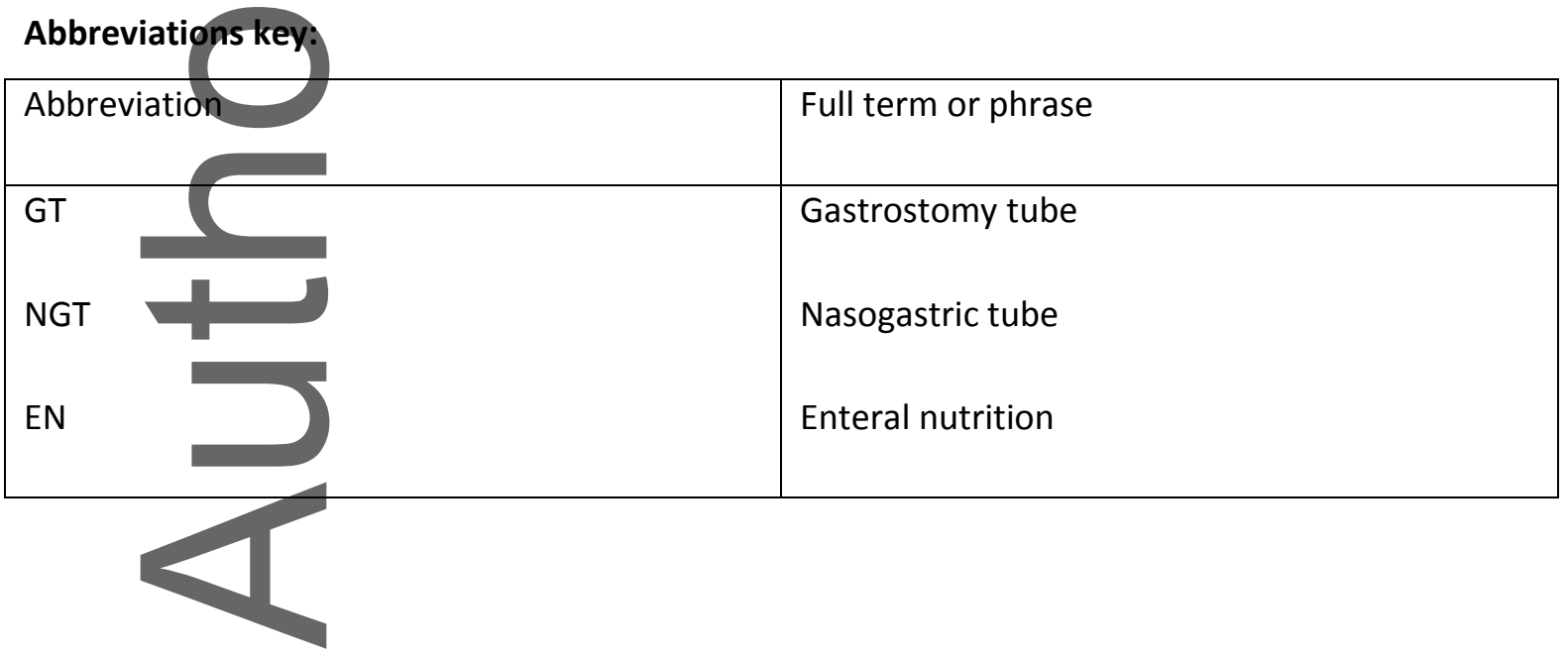

This is the author manuscript accepted for publication and has undergone full peer review but has not been through the copyediting, typesetting, pagination and proofreading process, which may lead to differences between this version and the Version of Record. Please cite this article as doi:

$10.1002 / \mathrm{pbc} .27702$.

This article is protected by copyright. All rights reserved. 


\section{Corresponding Author:}

Dr Kathleen H McGrath, FRACP, MBBS, BSc(Med)

Department of Gastroenterology and Clinical Nutrition

The Royal Children's Hospital, Parkville, VIC 3052, Australia

Email: mcgrath.kathleen@gmail.com

Phone: +447563249769

\section{Abstract}

Children with cancer are at risk of malnutrition which can impair critical childhood processes of growth and development and contribute to poor health outcomes. Enteral nutrition can effectively ameliorate malnutrition or weight loss in children with cancer, however published nutrition support algorithms contain minimal specific information on gastrostomy tube use and current literature is limited. Decisions about gastrostomy tube insertion in children with cancer can be challenging. Consideration of gastrostomy tube insertion is only appropriate in children with long term dependence on enteral nutrition, particularly when nasogastric tube insertion is predicted or proven to be problematic. Specific indications for patient selection are unclear and referring clinicians may be unaware of important absolute and relative contraindications. Complications are predominantly minor in nature; however reported rates are high. Morbidity must be weighed carefully against the need and anticipated duration of enteral nutrition support and further research in this area is needed.

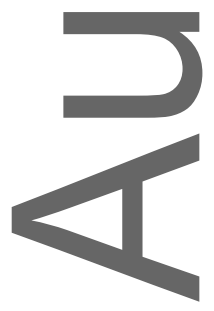




\section{Introduction}

All children with cancer are at risk of malnutrition, which may present at any stage from diagnosis, during treatment or into survivorship. The reported prevalence of malnutrition in children with cancer varies from 5.2 to $48 \%{ }^{1-4}$ Childhood is a critical period for growth, brain development, puberty and bone formation. Malnutrition may hinder these physiological childhood processes and has been associated with poorer survival outcomes, increased morbidity, increased episodes of febrile neutropenia with bacteraemia, reduced chemotherapy tolerance and lower physical, emotional and social functioning scores for health related quality of life. ${ }^{3,5-9}$ Children with malnutrition may have greater risk of long term health complications and comorbidities. ${ }^{10,11}$
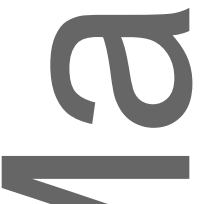

Risk factors formalnutrition may be cancer-specific e.g. diagnosis of a tumour associated with high nutritional risk because of its prolonged intense treatment course, or general nutritional risk factors e.g. severe malnutrition, presence of feeding problems or poor oral intake at diagnosis, dietary restrictions or exclusions, relevant comorbid medical or behavioural problems. Identification of risk factors should prompt consideration of the need for enteral hutrition (EN). Administration of EN is a safe and effective method of reversing malnutrition and preventing further weight loss in children with cancer. ${ }^{12-15}$ EN provides essential trophic factors to help maintain gastrointestinal mucosa, stimulates release of enterotrophic hormones and gastrointestinal secretions, and improves gallbladder motility. ${ }^{16-18}$ EN is most commonly provided through a nasogastric tube (NGT). In some children, NGT feeding may be problematic because of mechanical obstruction, NGT intolerance / refusal, or recurrent dislodgement, and the ability to provide effective EN may This article is protected by copyright. All rights reserved. 
be impaired. In these children, insertion of a gastrostomy tube (GT) may have a role when long term dependence on EN is predicted or needed. Despite GT insertion being a relatively straightforward procedure, correct patient selection, detailed pre-operative assessment and consistent post-operative management is important. Implementation of a standardised clinical pathway for GT insertion has been associated with decreased utilisation of hospital resources in a general paediatric population. ${ }^{19}$

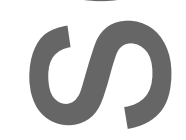

There is currently limited literature available on GT use in children with cancer and published nutrition support algorithms contain limited specific information on GT to guide clinicians with decision making. ${ }^{20-21}$ This article provides a comprehensive narrative review of current literature on GT use in children with cancer and summarises key considerations for clinicians in decision-making. Improved clinician understanding of the indications, risks and management of GT can facilitate appropriate, timely selection and referral of patients and minimise further risk of malnutrition.

\section{Methods}

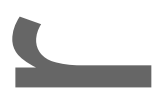

A comprehensive literature review was performed in November 2018 of the following databases: Medline (Ovid) and Embase (Ovid). Thesaurus and / or keywords were used as :

follows: (exp 'Neoplasm' (MeSH term) AND ('Gastrostomy' (MeSH term) OR 'Intubation, Gastrointestinal' (MeSH term) OR 'Enteral Nutrition' (MeSH term)). Results were limited to English language and children 0-18 years of age. PubMed was searched using keywords only to retrieve E-publications and items not indexed in Medline. The Medline search strategy 
was adapted for use in other databases. Additional items were identified through handsearching of reference lists of relevant retrieved articles.

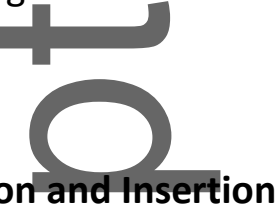

Indication and Insertion

Most current literature on GT use in cancer comes from studies of adults with head and neck cancers. ${ }^{22-27}$ The safety and efficacy of GT use in children with cancer has not been widely investigated but existing studies support it as an effective method of reversing malnutrition or preventing weight loss. ${ }^{28-31}$

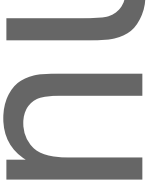

Methods ofinitial GT insertion include endoscopic (percutaneous endoscopic gastrostomy PEG) insertion, surgical open or laparoscopic placement and interventional radiological

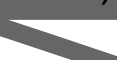

technique. Choice of technique is influenced by local resources, expertise and safety profiles.

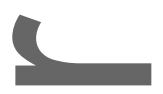

Children should be screened for nutritional risk at the time of diagnosis and reviewed throughout periods of cancer treatment. The child's baseline nutritional state, previous feeding difficulties or dietary restrictions and any comorbid medical or behavioural problems should be assessed to determine presence of malnutrition and indications for nutritional support. Consideration should also be given to the underlying cancer diagnosis and anticipated duration, type and intensity of treatment to predict future nutritional risk or need for nutritional support and the anticipated duration of EN. Childhood cancers associated with a high nutritional risk, when EN is more likely to be required, include: 
Osteosarcoma, Ewing sarcoma, high risk or pelvic rhabdomyosarcoma, high risk primitive neuroectodermal tumour, medulloblastoma or high risk brain tumours (e.g. diencephalic (

tumours), multiple relapsed or high risk leukaemia or lymphoma, patients undergoing Haematopoietic Stem Cell Transplant (HSCT), head and neck tumours, high risk Wilms tumour or Neuroblastoma. ${ }^{13,32}$

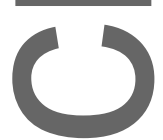

Options fornutrition support in children with predicted short-term requirement include oral nutritional supplements, EN given via NGT, or parenteral nutrition in the presence of a nonfunctionalgastrointestinal tract. Consideration of GT insertion is usually only appropriate for children with predicted long term dependence on EN given the associated risks and healing time, as discussed in detail below. Long term EN is defined as greater than 3-months duration in our institution and other nutrition support algorithms, ${ }^{21}$ however shorter

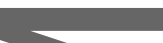
periods (greater than 6 weeks) have been published as an appropriate threshold for considering GT insertion. ${ }^{20}$

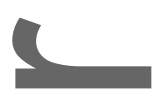

When nutritional assessment predicts long term dependence on EN, alternative administration routes for EN should be discussed between nutritionist, oncologist, patient and parent/carer at an early stage, preferably soon after diagnosis. Older children and parents/carers should be provided with information or decision aids containing information on relevant differences between NGT and GT (Table 1) and involved in decisionmaking. In most instances, NGT will be appropriate and selected as the preferential route for EN administration. However, in certain circumstances NGT may be predicted to be problematic including potential mechanical obstruction of gastrointestinal tract from head and neck tumour, patient or parent / carer intolerance or refusal of NGT or predicted 
recurrent dislodgement of NGT. Some patients may express strong preference for a GT over NGT e.g. adolescents concerned about the cosmetic impact of a NGT or parents concerned chestiberat about deliberate dislodgement by the child. Further, NGT feeding may be initiated but prove problematic later in treatment because of recurrent NGT dislodgement by treatment induced emesis. This should prompt reconsideration of the predicted duration of EN and possible role for GT insertion.

\section{$\mathcal{C}$}

Approaches to timing of GT insertion include proactive insertion (based on predicted nutritional risk), or reactive insertion (once malnutrition occurs, usually during cancer treatment). Both approaches have been published in the literature but study numbers and size and generally small. One study retrospectively compared reactive versus proactive PEG insertion in children with bone tumours and showed prevention of weight loss and weight stabilisation but no overall impact on height variation or significant difference in PEG tolerance and complication rates between the groups. ${ }^{31}$ Another recent retrospective study showed early proactive GT insertion in children with primary bone cancer was effective for administering nutritional support and better at avoiding early deterioration in nutritional status compared with NGT EN or no EN however there was no significant difference in 4year survival between the groups. ${ }^{33}$

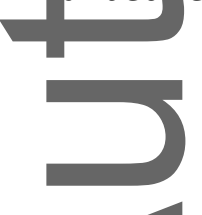

\section{Contraindications}

Not all patients are suitable for GT insertion. Any potential contraindications identified during the process of clinical assessment should be clearly communicated within the care team (nutrition support, oncologist) (see Table 2). The safest method of insertion may vary 
with the clinical circumstances. Relevant information that should be included in initial GT referrals in children with cancer to assist decision making and scheduling, includes: cancer diagnosis, previous abdominal surgery, presence of ventriculo-peritoneal (VP) shunt, bleeding risk (current parameters for platelet count and coagulation studies), infection risk, date of most recent (if applicable) and next planned chemotherapy / radiotherapy and date of next expected neutropenia. The proceduralist will then be able to identify the safest method of insertion in order to minimise unnecessary risk.

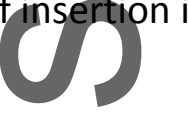

Table 2 outlines absolute contraindications to PEG tube insertion. ${ }^{34}$ In the presence of relative contraindications including previous abdominal surgery, organomegaly or kyphoscoliosis, alternative methods (e.g. surgical open or laparoscopic technique) or timing of GT insertion should be considered. ${ }^{34}$

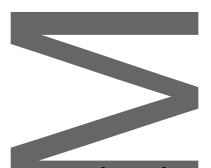

Children with a brain tumour and ventriculo-peritoneal (VP) shunt require special consideration of increased infection risk (shunt infection, peritonitis) with GT insertion. A retrospective study of 26 GT insertions (technique unspecified) in 25 children, 11 of whom also had a VP shunt showed 1 case of shunt infection that could be attributed to GT insertion. ${ }^{35}$ Another retrospective study of children with CNS tumours and VP shunts found a higher rate of VP shunt infection in those children with a GT (radiologically inserted) (4/17; $23.5 \%)$ than those without a GT $(3 / 34 ; 8.8 \%)$. Most of the VP shunt infections (3/4) occurred when the GT was inserted within 6 weeks of VP shunt insertion and the authors recommend delayed GT insertion until after the acute healing phase (greater than 6 weeks) for the VP shunt. $^{36}$ 


\section{Complications}

Reported complications rates associated with GT insertion in children with cancer are high $(60-90 \%)^{33,37-41}$ compared with rates reported in adults with cancer (predominantly head and neck cancer). ${ }^{24-26,31,42}$ Reports of complication rates of GT insertion in children with cancer compared with other children (predominantly with neurological impairment) are conflicting.Some studies show no significant difference overall however others support significant/yhigher risk of wound infection or inflammation in children with cancer. ${ }^{31,34,43,44}$ Reported rates of major complications (fatal or resulting in major patient discomfort, repeat procedure, surgical intervention or hospitalization) vary from $7-13 \%$ and are similar between children with cancer requiring a GT and those with a non-cancer diagnosis. ${ }^{29,31,44}$ (1)

Table 3 summarises minor and major complications associated with GT, including perioperative risks and late complications. Risks should be carefully discussed with the patient and parent/care prior to insertion including institutional specific information when available, and weighed carefully against the need and alternative options for nutrition support.

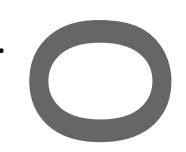

Complications are predominantly minor in nature and may be early (within 30 days of insertion) or late (beyond 30 days of insertion). Higher complication rates have been described in younger patients. ${ }^{38}$ Gastrostomy site skin infection or inflammation are the most frequently reported minor complication but the retrospective nature of studies can limit the ability to distinguish between these two entities from medical record documentation alone which can also be a challenge encountered in clinical practice. ${ }^{29,37,38,41,45,46}$ Correlation between gastrostomy skin site infection or inflammation 
and administration of cytostatic drugs / neutropenia is conflicting despite frequent concerns about this in clinical practice. Study numbers are frequently small, limiting ability for statistical analysis and further large cohort prospective studies are needed..$^{31,37,43}$ Stoma site infections have been significantly associated with malnutrition. ${ }^{41}$ Antibiotic prophylaxis at insertion with classic 'pull technique' has been shown to reduce incidence of wound infection and post-operative inflammatory complications in adults. ${ }^{34}$

\section{(}

A recent systematic review of all paediatric populations showed a significantly higher risk of major complications in PEG compared with laparoscopically placed GT however most included studies were retrospective. ${ }^{47}$ Data specific to children with cancer is limited and must be interpreted with caution. One retrospective study showed a higher rate of postoperative complications in PEG tubes $(n=28)$ compared with openly placed $G T(n=84)$ in children with cancer. ${ }^{39}$ Another retrospective study reported a significantly higher infection rate in GT placed by open surgical technique compared with those placed endoscopically or laparoscopically. ${ }^{38}$

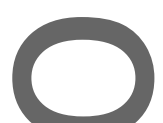

Button GT are not commonly used at initial insertion and there is limited evidence on their use in children with cancer. A small feasibility study of radiologically placed primary button GT in 11 children and young adults with cancer (3-20 years old) showed no major complications or short to medium term infections and minor complications in only two patients. ${ }^{48}$ However, another study showed much higher rates of local infection with button GT use compared with initial GT highlighting the need for further research. ${ }^{40}$ 
The incidence of persistent gastrocutaneous fistula after GT removal has been reported as high as $45 \%$ in general paediatric populations, with duration since initial insertion the only

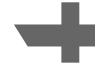
reported significant predictive factor. ${ }^{38}$ There are no documented rates specific to children with cancer, however the effects of malnutrition, immunosuppression and chemotherapy may all play a role in wound healing and further specific studies are needed in this population.

Discussion

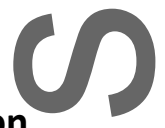

Successful administration of nutrition support therapy relies on access to multidisciplinary team support and adequate resources to engage patients, their parents / carers and reinforce understanding of the potential benefits. ${ }^{49,50}$ Enteral tube feeding is commonly initiated as a reactive measure to weight loss or malnutrition, however proactive enteral (n)

tube feeding has been shown to be feasible and associated with improved nutritional outcomes, ${ }^{51,52}$ reduced non-leukopenic infections in the subsequent period ${ }^{53}$ and improved EN tolerance following HSCT. ${ }^{54}$ There is currently inadequate evidence to conclude whether one approach is superior to the other in children with cancer and further research is needed.

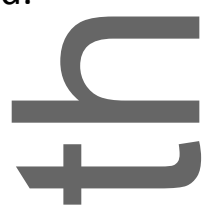

Standardisation of post-operative care for GT through common clinical pathways may improve outcomes (although institutional variation in resources and preferred insertion techniques will influence local decision making). ${ }^{19}$ Early post-operative education should include care of the GT, stoma and surrounding skin, need for regular GT flushes after bolus feeds or medication administration and an action plan for accidental dislodgement. Pump 
training should be provided to the parent / carer if the child has not already been on NGT feeds at home and arrangements made for formula provision and equipment supplies. in

Administration of medications via the GT should be explained. Appropriate follow up should be scheduled with staff trained in gastrostomy care to assess for complications such as granulation tissue, local inflammation or infection. The position of the external GT flange should be closely monitored. Children with cancer may have rapid weight gain in the weeks to months following GT insertion and their stomal length may increase. When the GT appears tight, the external GT flange should be carefully loosened by trained staff to avoid excessive pressure on the skin and associated discomfort, as well as minimise tension on the internal GT flange which may be a risk factor for migration of the internal GT flange out of the stomach, a complication commonly referred to as a 'buried bumper'.

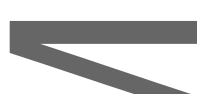

Literature specifically on the use of GT in children with cancer is limited and predominantly retrospective. The challenges of clinical research in nutrition support are inherent to this area and there is considerable variability in methodology between current studies including study population, methods of nutritional assessment, definition of malnutrition, nutritional outcomes assessed and timing and technique of GT insertion. This may limit reliability of results or capacity to apply findings to clinical practice. This review provides a summary of current literature on this topic but highlights the need for high quality studies looking at GT use in children with cancer. Future research should include prospective studies comparing outcomes (nutritional, quality of life / patient experience, cancer outcomes) in children with cancer receiving EN by GT with those receiving NGT EN. Further, different techniques of GT 
insertion should be compared to enable evidence-based standardisation of care when possible.

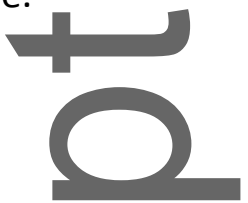

Using the literature currently available and our experience, we have summarised key considerations for clinicians regarding GT insertion and management in children with cancer (Fig. 1). Informed understanding of the associated risks and complications by patients and their parents / carers, especially at a time where there can be 'information overload' following a new eancer diagnosis, is paramount. Future development of decision aids and written information specific for this group is important. This summary is not intended to be a strict guideline, but rather a clinical tool to highlight aspects not to be missed pre and post GT insertion in children with cancer and that may have a significant impact on safety and outcomes. It is hoped that improved understanding will assist prompt identification of suitable patients, minimise unnecessary complications / risk and facilitate timely provision of EN.

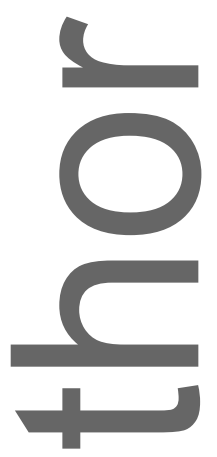

Conflicts of interest Statement: The authors have no conflicts of interest to declare.

Acknowledgements: None

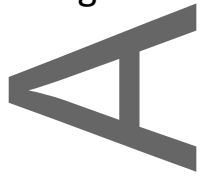


${ }^{1}$ Brinksma A, Roodbol PF, Sulkers E, Kamps WA, de Bont ESJM, Boot AM, Burgerhof JGM, Tamminga RYJ, Tissing WJE. Changes in nutritional status in childhood cancer patients: A prospective cohort study. Clin Nut 2015;34:66-73.

${ }^{2}$ Galati PC, Resende CMM, Salomao RG, Scridelli CA, Tone LG, Monteiro JP. Accurate determination of energy needs in children and adolescents with cancer. Nutr Cancer 2011;63(2):306-313.

${ }^{3}$ Loeffen EAH, Brinksma A, Miedema KGE, de Bock GH, Tissing WJE. Clinical implications of malnutrition in childhood cancer patients- infections and mortality. Support Care Cancer 2015;23:143-150.

${ }^{4}$ Murphy AJ,White M, Elliott SA, Lockwood L, Hallahan A and Davies PSW. Body composition of children with cancer during treatment and in survivorship. Am J Clin Nutr 2015;102:891-896.

${ }^{5}$ Brinksma A, Sanderman R, Roodbol PF, Sulkers E, Burgerhof JGM, de Bont ESJM, Tissing WJE. Malnutrition is associated with worse health-related quality of life in children with cancer. Support Care Cancer 2015;23:30433052.

${ }^{6}$ Lobato-Mendizabal E, Lopez-Martinez B, Ruiz-Arguelles GJ. A critical review of the prognostic value of the nutritional status at diagnosis in the outcome of therapy of children with acute lymphoblastic leukemia. Rev Invest Clin 2003;55(1):31-35.

${ }^{7}$ Butturini AM, Dorey FJ, Lange BJ et al. Obesity and outcome in pediatric acute lymphoblastic leukemia. J Clin Oncol 2007;25(15):2063-2069.

${ }^{8}$ Orgel E, Sposto R, Malvar J, Seibel NL, Ladas E, Gaynon PS, Freyer DR. Impact on survival and toxicity by duration of weight extremes during treatment for pediatric acute lymphoblastic leukemia: A report from the Children's Oncology Group. J Clin Oncol 2014;32:1331-1337.

${ }^{9}$ Sala A, Rossí E, Antillon F, Molina AL, de Maselli T, Bonilla M, Hernandez A, Ortiz R, Pacheco C, Nieves R, Navarrete M, Barrantes M, Pencharz P, Valsecchi MG, Barr R. Nutritional status at diagnosis is related to clinical outcomes in children and adolescents with cancer: A perspective from Central America. Eur J Cancer 2012;48:243-252.

${ }^{10}$ Armstrong GT, Oeffinger KC, Chen Y, Kawashima T, Yasui Y, Leisenring W, Stovall M, Chow EJ, Sklar CS, Mulrooney DA et al. Modifiable risk factors and major cardiac events among adult survivors of childhood cancer. JClin Oncol 2013;31:3673-3680.

${ }^{11}$ Nolan CG, KrullKR, Gurney JG, Leisenring W, Robison LL, Ness KK. Predictors of future health-related quality of life in survivors of adolescent cancer. Pediatr Blood Cancer 2014;61:1891-1894.

${ }^{12}$ DeSwarte-Wallace J, Firouzbakhsh S, Finklestein JZ. Using research to change practice: enteral feedings for pediatric oncology patients. J Pediatr Oncol Nurs 2001;18(5):217-223.

${ }^{13}$ Ladas EJ, N Sacks, Meacham L, Henry D, Enriquez L, Lowry G, Hawkes R, Dadd G, Rogers P. A multidisciplinary review of nutrition considerations in the pediatric oncology population: a perspective from children's oncology group. Nutr Clin Pract 2005;20(4):377-393.

${ }^{14}$ Pietsch JB, Ford C, Whitlock JA. Nasogastric tube feedings in children with high-risk cancer: A pilot study. J Pediatr Hematol Oncol 1999;21(2): 111-114.

${ }^{15}$ Trimpe K, Shaw MR, Wilson M, Haberman MR. Revie wof the effectiveness of enteral feeding in pediatric oncology patients. J Pediatr Oncol Nurs 2017;34(6):439-445.

${ }^{16}$ Christensen ML, Hancock ML, Gattuso J, Hurwitz CA, Smith C, McCormick J, Mirro J. Parenteral nutrition associated with increased infection rate in children with cancer. Cancer 1993;72:2732-2738.

${ }^{17}$ Goulet O, Ruemmele F, Lacaille F, Colomb V. Irreversible intestinal failure. J Pediatr Gastroenterol Nutr 2004;38:250-26

${ }^{18}$ Ohta K, Omura K, Hirano K, Kanehira E, Ishikawa N, Kato Y, Kawakami K, Watanabe G. The effects of an additive small amount of a low residue diet against total parenteral nutrition-induced gut mucosal barrier. Am J Surg 2003;185:79-85.

${ }^{19}$ Richards MK, Li Cl, Foti JL, Leu MG, Wahbeh GT, Shaw D, Libby AK, Melzer L, Goldin AB. Resource utilisation after implementing a hospital-wide standardized feeding tube placement pathway. J Pediatr Surg 2016;51:1674-1679.

${ }^{20}$ Steele C, Salazar A, Rypkema L. Utilization of a Nutrition Support Algorithm Reduces Unnecesary Parenteral Nutrition Use in Pediatric Oncology Inpatients. J Acad Nutr Diet 2016;116(8):1235-1238. Available from http://dx.doi.org/10.1016.j.jand.2015.12.007.

${ }^{21}$ Bowman LC, Williams R, Sanders M, Ringwald-Smith K, Baker D, Gajjar A. Algorithm for nutritional support: experience of the metabolic and infusion support service of St Jude Children's Research Hospital. In J Cancer 1998;Supp 11:76-80.

This article is protected by copyright. All rights reserved. 
${ }^{22}$ Atasoy BM, Yonal O, Demirel B, Dane F, Yilmaz Y, Kalayci C, Abacioglu U, Imeryuz N. The impact of early percutaneous endoscopic gastrostomy placement on treatment completeness and nutritional status in locally advanced head and neck cancer patients receiving chemoradiotherapy. Eur Arch Otorhinolaryngol

2012;269(1):275-82,

${ }^{23}$ Brown TE, Getliffe V, Banks MD, Hughes BGM, Lin CY, Kenny LM, Bauer JD. Validation of an updated evidence-based protocol for proactive gastrostomy tube insertion in patients with head and neck cancer. Eur J Clin Nutr 2016;70:574-581.

${ }^{24} \mathrm{Hin}$ PC. Laparoscopic-assisted gastrostomy in 26 patients: Indications and outcome at 2 years. J Laparoendosc Surg 1996;6(1): 25-28.

${ }^{25}$ Lin HS, Ibrahim HZ, Kheng JW, Fee WE, Terris DJ. Percutaneous endoscopic gastrostomy: Strategies for prevention and management of complications. Laryngoscope 2001;111(10): 1847-1852.

${ }^{26}$ Mansoor $\mathrm{H}$, Masood MA, Yusuf MA. Complications of percutaneous endoscopic gastrostomy tube insertion in cancer patients: a retrospective study. J Gastrointest Cancer 2014;45(4):452-459.

${ }^{27}$ Zhang Z, Zhu Y, Ling Y, Zhang L, Wan H. Comparative effects of different enteral feeding methods in head and neck cancer patients receiving radiotherapy or chemoradiotherapy: a network meta-analysis. Onco Targets Ther 2016;9:2897-2909.

${ }^{28}$ Aquino VM, Smyrl CB, Hagg R, McHard KM, Prestridge L, Sandler ES. Enteral nutrition support by gastrostomy tube in children with cancer. J Pediatr 1995;127(1):58-62.

${ }^{29}$ Barron MA, Duncan DS, Green GJ, Modrusan D, Connolly B, Chait P, Saunders EF, Greenberg M. Efficacy and safety of radiologically placed gastrostomy tubes in paediatric haematology/oncology patients. Med Pediatr Oncol 2000;34(3): 177-182.

${ }^{30}$ Phen C, Amre D, Oshrine B, Wilsey M. Sa2083 Safety and Efficacy of Percutaneous Endoscopic Gastrostomy Feedings in Malnourished Pediatric Cancer Patients [Abstract]. Gastrointest Endosc 2017;85(5):AB289.

${ }^{31}$ Schmitt F,Caldari D, Corradini N, Gicquel P, Lutz P, Leclair MD, Podevin G. Tolerance and efficacy of preventive gastrostomy feeding in pediatric oncology. Pediatr Blood Cancer 2012;59(5):874-80.

${ }^{32}$ Bauer J, Jurgens $\mathrm{H}$, and Fruhwald MC. Important aspects of nutrition in children with cancer. Adv. Nutr 2011;2:67-77

${ }^{33}$ Henry C, Dumoucel S, Taque S, Esvan M, Pellier I, Minckes O, Blouin P, Carausu L, Gandemer V. Evaluation of early gastrostomy in the management of tumeurs osseuses primitives malignes de l'enfant.primary malignant bone tumors of the child. Expérience du groupe Assessment of early gastrostomy in the treatment of primary malignant bone tumours in children. A report from the French children's oncology study group GOCE. Revue d'oncologie hematologie pediatrique 2017;5(1):10-20. (English abstract only, article in French)

${ }^{34}$ Heuschkel RB, Gottrand F, Devarajan K, Poole H, Callan J, Dias JA, Karkelis S, Papadopoulou A, Husby S, Ruemmele F, Schappi MG, Wilschanski M, Lionetti P, Orel R, Tovar J, Thapar N, Vandenplas Y. ESPGHAN Position paper on management of percutaneous endoscopic gastrostomy in children and adolescents. J Pediatr Gastroenterol Nutr 2015;60(1):131-141.

${ }^{35}$ Bakish J, Hargrave D, Tariq N, Laperriere N, Rutka JT, Bouffet E. Evaluation of dietetic intervention in children with medulloblastoma or supratentorial primitive neuroectodermal tumors. Cancer 2003;98(5):1014-1020.

${ }^{36}$ Gassas A, Kennedy J, Green G, Connolly B, Cohen J, Dag-Ellams U, Kulkarni A, Bouffet E. Risk of ventriculoperitoneal shunt infections due to gastrostomy feeding tube insertion in pediatric patients with brain tumors. Pediatr Neurosurg 2006;42(2), 95-99.

${ }^{37}$ Bisgaard Pedersen AM, Kok K, Peterson G, Nielsen OH, Michaelsen KF, Schmiegelow K. Percutaneous endoscopic gastrostomy in children with cancer. Acta Paediatr 1999;88:849-852.

${ }^{38}$ Fernandez-Pinedal, Sandoval JA, Jones RM, Boateng N, Wu J, Rao BN, Davidoff AM, Shochat SJ. Gastrostomy Complications in Pediatric Cancer Patients: A Retrospective Single-Institution Review. Pediatr Blood Cancer 2016;63(7):1250-1253.

${ }^{39}$ Hamilton EC, Curtin T, Slack RS, Ge C, Slade AD, Hayes-Jordan A, Lally, KP, Austin MT. Surgical Feeding Tubes in Pediatric and Adolescent Cancer Patients: A Single-institution Retrospective Review. J Pediatr Hematol Oncol 2017;39(7):342-348.

${ }^{40}$ Mathew-P, Bowman L, Williams R, Jones D, Rao B, Schropp K, Warren B, Klyce MK, Whitington G, Hudson M. Complications and effectiveness of gastrostomy feedings in pediatric cancer patients. J Pediatr Hematol Oncol 1996;18(1):81-85.

${ }^{41}$ Parbhoo DM, Tiedemann K, Catto-Smith AG. Clinical outcome after percutaneous endoscopic gastrostomy in children with malignancies. Pediatr Blood Cancer 2011;56:1146-1148.

${ }^{42}$ Ponsky JL, Gauderer MW, Stellato TA. Percutaneous endoscopic gastrostomy. Review of 150 cases. Arch Surg 1983;118:913-914.

This article is protected by copyright. All rights reserved. 
${ }^{43}$ Arnbjornsson E, Backman T, Morse H, Berglund Y, Kullendorff CM, Lovkvist H. Complications of videoassisted gastrostomy in children with malignancies or neurological diseases. Acta Paediatr 2006;95(4):467470.

${ }^{44}$ Fox VL, Abel SD, Malas S, Duggan C, Leichtner AM. Complications following percutaneous endoscopic gastrostomy and subsequent catheter replacement in children and young adults. Gastrointest Endosc 1997;45(1):64-71.

${ }^{45}$ Pedersen AM, Kok K, Petersen G, Nielsen OH, Michaelsen KF, Schmiegelow K. Percutaneous endoscopic gastrostomy in children with cancer. Acta Paediatr 1999;88(8):849-852.

${ }^{46}$ Skolin 1, Hernell O, Larsson MV, Wahlgren C, Wahlin YB. Percutaneous endoscopic gastrostomy in children with malignant disease. J Pediatr Oncol Nurs 2002;19(5):154-163.

${ }^{47}$ Baker L, Beres AL, Baird R. A systematic review and meta-analysis of gastrostomy insertion techniques in children. J Pediatr Surg 2015;50:718-725.

${ }^{48}$ Richioud B, Louazon T, Beji H, Bertrand A, Roux P, Kalenderian A-C, Cuinet M, Pilleul F, Marec-Berard P. De novo radiologic placement of button gastrostomy: a feasibility study in children with cancer. Pediatr Radiol 2015;45:1957-1963.

${ }^{49}$ Azarnoush S, Bruno B, Beghin L, Guimber D, Nelken B, Yakoub-Agha I, Seguy D. Enteral nutrition: a first option for nutritional support of children following allo-SCT? Bone Marrow Transplant 2012;47(9):1191-1195.

${ }^{50}$ Langdana A, Tully N, Molloy E, Bourke B, O'Meara A. Intensive enteral nutrition support in paediatric bone marrow transplantation 2001;27:741-746.

${ }^{51}$ Sacks N, Hwang W-T, Lange BJ, Tan K-S, Sandler ES, Rogers PC, Womer RB, Pietsch JB, Rheingold SR.

Proactive enteral tube feeding in pediatric patients undergoing chemotherapy. Pediatr Blood Cancer 2014;61:281-285.

${ }^{52}$ Ward E; Hopkins M; Arbuckle L; Williams N; Forsythe L; Bujkiewicz S; Pizer B; Estlin E; Picton S. Nutritional problems inchildren treated for medulloblastoma: implications for enteral nutrition support. Pediatr Blood Cancer 2009;53(4):570-5.

${ }^{53}$ den Broeder E; Lippens RJ; van't Hof MA; Tolboom JJ; Sengers RC; van Staveren WA. Association between the change in nutritional status in response to tube feeding and the occurrence of infections in children with a solid tumor. Pediatr Hematol Oncol 2000;17(7):567-75.

${ }^{54}$ Seguy D, Berthon C, Micol J-B, Darre S, Dalle J-H, Neuville S et al. Enteral feeding and early outcomes of patients undergoing allogenic stem cell transplantation following myeloablative conditioning. Transplantation 2006;82:835-839.

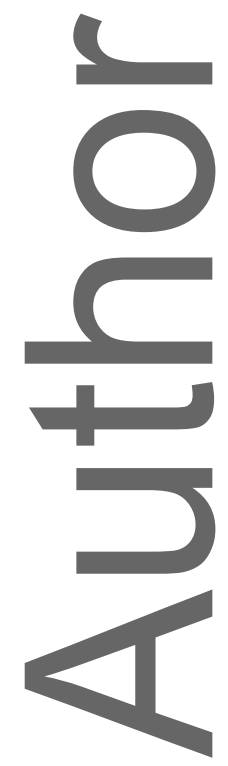

This article is protected by copyright. All rights reserved. 


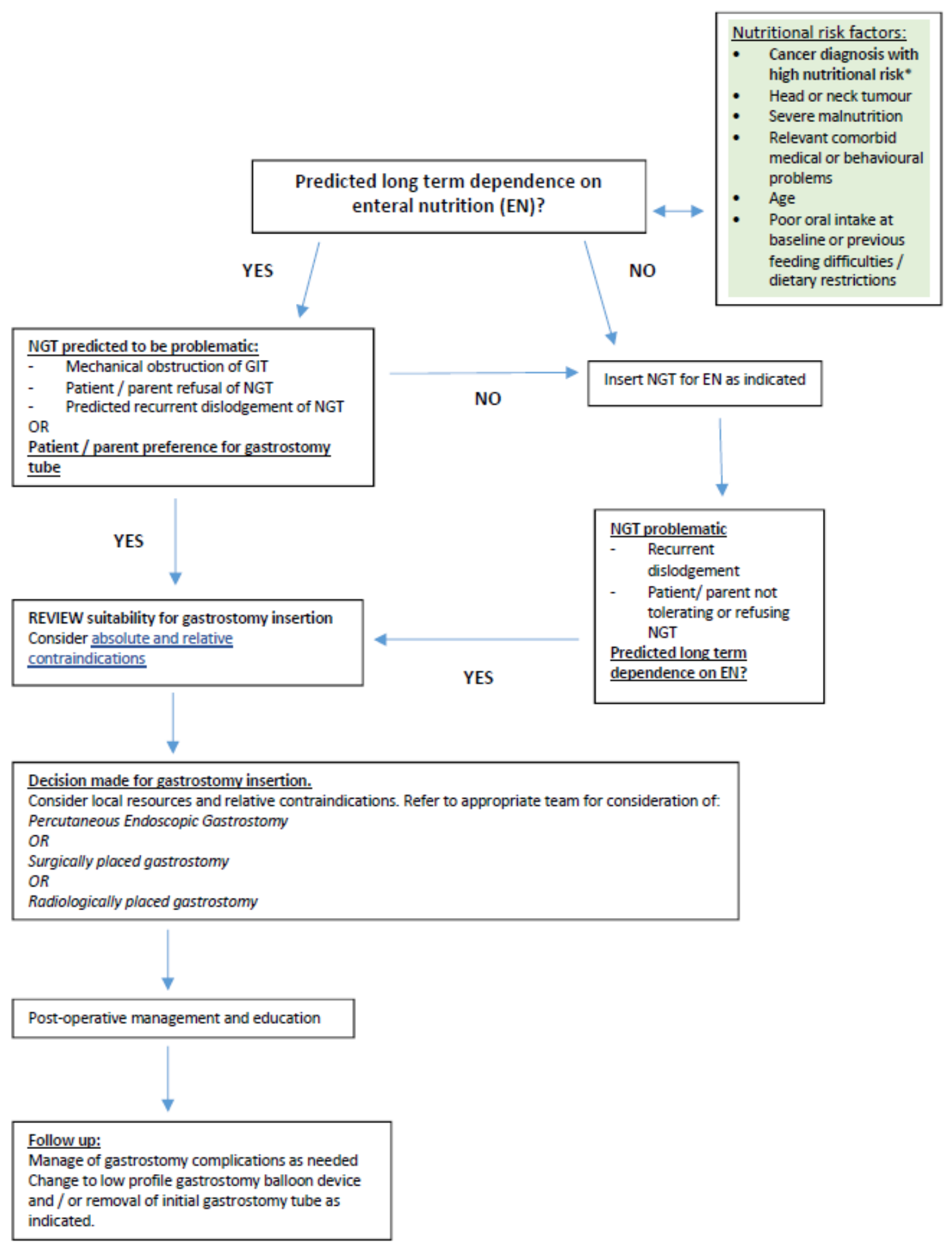

* Osteosarcoma, Ewing sarcoma, high risk or pelvic rhabdomyosarcoma, high risk primitive neuroectodermal tumour, medulloblastoma or high risk brain tumours, multiple relapsed or high risk leukaemia or lymphoma, patients undergoing Haematopoeitic Stem Cell transplant, high risk Wilms tumour or neuroblastoma

Figure 1 Summary of key considerations for gastrostomy tube insertion and management in children with cancer.

This article is protected by copyright. All rights reserved. 
TABLE 1 Differences between nasogastric tubes and gastrostomy tubes to discuss with patients and their parent / carer.

\begin{tabular}{|c|c|c|}
\hline & Nasogastric tube & Gastrostomy tube \\
\hline Insertion & $\begin{array}{l}\text { Quick } \\
\text { Can be done at bedside or with } \\
\text { sedation }\end{array}$ & $\begin{array}{l}\text { Requires general anaesthetic for } \\
\text { insertion }\end{array}$ \\
\hline Cosmetic & & Can be concealed under clothes \\
\hline Dislodgement & $\begin{array}{l}\text { Common with vomiting } \\
\text { Reinsertion may be delayed by } \\
\text { bleeding / infection risk }\end{array}$ & Very uncommon \\
\hline Complications & $\begin{array}{l}\text { Mild discomfort } \\
\text { Uncommon and usually mild }\end{array}$ & Common but usually mild \\
\hline Oral skill development & & $\begin{array}{l}\text { May encourage chance for oral skill } \\
\text { development }\end{array}$ \\
\hline Replacement & $\begin{array}{l}\text { Common reasons include } \\
\text { dislodgement / blockage. } \\
\text { Long term tubes require reinsertion } \\
\text { every 1-2 months. }\end{array}$ & $\begin{array}{l}\text { Requires general anaesthetic for } \\
\text { removal (may change to low profile } \\
\text { device if ongoing need for enteral } \\
\text { nutrition) }\end{array}$ \\
\hline
\end{tabular}

TABLE 2 Absolute contraindications for Percutaneous Endoscopic Gastrostomy insertion in children with cancer and relative contraindications that may require consideration of different methods or timing of gastrostomy tube insertion. ${ }^{34}$

\begin{tabular}{|c|c|}
\hline Absolute & Relative \\
\hline $\begin{array}{ll}\text { - } & \text { Active peritonitis } \\
\text { - } & \text { Significant coagulopathy that cannot be } \\
\text { corrected (INR }>1.5, \text { APPT }>50, \text { platelets }<50) \\
\text { - } \quad \text { Clear interposition of enlarged organs }\end{array}$ & $\begin{array}{ll}- & \text { Hepatosplenomegaly } \\
\text { - } & \text { History of oesophageal stricture } \\
\text { - } & \text { Active oral candidiasis } \\
\text { - } & \text { Active gastritis or peptic ulcer disease } \\
\text { - } & \text { History of large oesophageal or gastric varices } \\
\text { - } & \text { Active severe mucositis } \\
\text { - } & \text { Portal hypertension } \\
- & \text { Ascites } \\
- & \text { VP shunt } \\
- & \text { Peritoneal dialysis } \\
- & \text { Morbid obesity (>95 } 5^{\text {th }} \text { centile) } \\
- & \text { Severe kyphoscoliosis } \\
- & \text { Previous abdominal surgery } \\
- & \text { Bleeding risk (liver disease, malabsorption, } \\
& \text { severe malnutrition, immunosuppression, } \\
\text { coagulation factor deficiency) }\end{array}$ \\
\hline
\end{tabular}


TABLE 3 Major and minor complications of gastrostomy tubes in children.

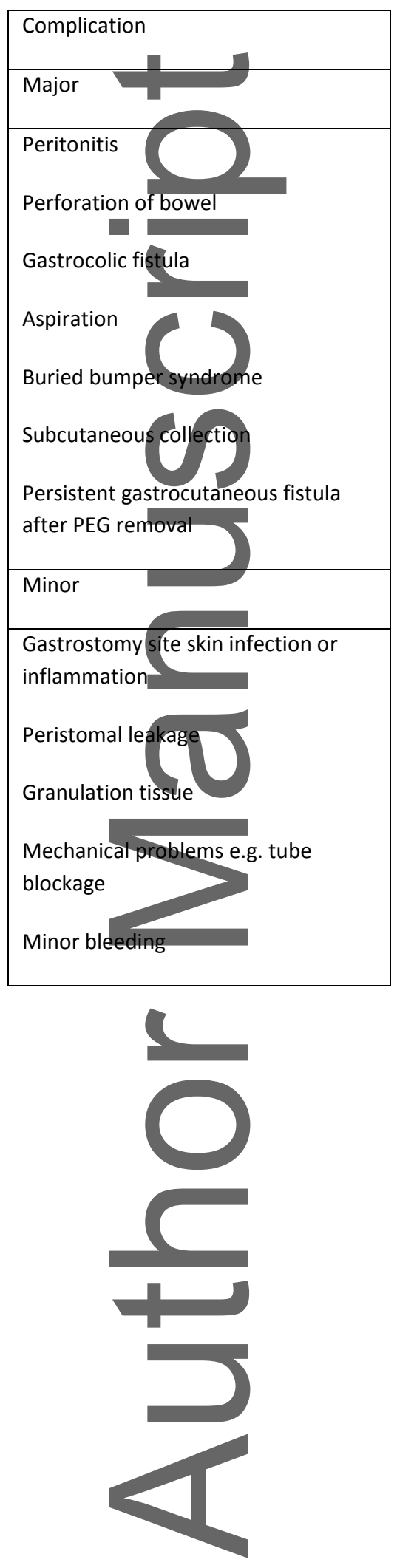

This article is protected by copyright. All rights reserved. 


\section{University Library}

\section{- M M I E E R VA A gateway to Melbourne's research publications}

Minerva Access is the Institutional Repository of The University of Melbourne

Author/s:

McGrath, KH;Hardikar, W

Title:

Gastrostomy tube use in children with cancer

Date:

2019-07-01

Citation:

McGrath, K. H. \& Hardikar, W. (2019). Gastrostomy tube use in children with cancer.

PEDIATRIC BLOOD \& CANCER, 66 (7), https://doi.org/10.1002/pbc.27702.

Persistent Link:

http://hdl.handle.net/11343/285570 